\title{
BAFF- and APRIL-targeted therapy in systemic autoimmune diseases
}

\author{
Shingo Nakayamada and Yoshiya Tanaka*
}

\begin{abstract}
B cells play a pivotal role in autoimmunity not only by producing pathogenic autoantibodies but also by modulating immune responses via the production of cytokines and chemokines. The B cell-activating factor/a proliferation-inducing ligand (BAFF/APRIL) system promotes B cell survival and differentiation and thus plays a prominent role in the pathogenesis of autoimmune diseases. Currently, BAFF and APRIL inhibitors are in clinical trials for systemic lupus erythematosus with significant efficacy. However, several studies have demonstrated the efficacy of the BAFF/APRIL blockade which showed considerable variability in the response to B cell-targeted therapy. This may indicate substantial heterogeneity in the pathogenesis of autoimmune diseases. Therefore, objective markers that can predict the effect of BAFF/APRIL-blocking agents could be valuable to the precision medicine linked clinically and to cost-effective therapy.
\end{abstract}

Keywords: BAFF, APRIL, B cells, Tfh cells, Autoimmune diseases

\section{Background}

Systemic autoimmune diseases are pathologically characterized by immune complexes consisting of antigens, the activation of dendritic cells and autoreactive $\mathrm{T}$ cells, and the overproduction of autoantibodies secreted from activated B cells, which cause severe inflammation in various organs [1]. Although the survival of patients with autoimmune diseases has improved over the past 50 years with conventional treatments such as immunosuppressants and corticosteroids, these drugs are limited by inefficacy and intolerance in some patients. Since several autoimmune diseases such as systemic lupus erythematosus (SLE) and ANCA-associated vasculitis (AAV) remain an important cause of mortality and morbidity, innovative therapeutic approaches need to be developed.

$\mathrm{B}$ cells play a pivotal role in the pathogenesis of autoimmune diseases not only by producing pathogenic autoantibodies but also by modulating immune responses via production of cytokines and chemokines [2]. The potential efficacy of B cell depletion therapy has been reported in several autoimmune diseases. Rituximab, a chimeric anti-CD20 antibody, eliminates

\footnotetext{
* Correspondence: tanaka@med.uoeh-u.ac.jp
The First Department of Internal Medicine, School of Medicine, University of

* Correspondence: tanaka@med.uoeh-u.ac.jp
The First Department of Internal Medicine, School of Medicine, University of Occupational and Environmental Health, 1-1 Iseigaoka, Yahata-nishi, Kitakyushu 807-8555, Japan
}

(c) 2016 Nakayamada and Tanaka. Open Access This article is distributed under the terms of the Creative Commons Attribution 4.0 International License (http://creativecommons.org/licenses/by/4.0/), which permits unrestricted use, distribution, and reproduction in any medium, provided you give appropriate credit to the original author(s) and the source, provide a link to the Creative Commons license, and indicate if changes were made. The Creative Commons Public Domain Dedication waiver (http://creativecommons.org/publicdomain/zero/1.0/) applies to the data made available in this article, unless otherwise stated. antibody- and complement-dependent cytotoxic activities [3]. In Japan, rituximab is approved for clinical use in childhood refractory nephrotic syndrome and AAV such as granulomatosis with polyangiitis (GPA) and microscopic polyangiitis (MPA). Despite expectations, large randomized controlled clinical trials of rituximab for non-renal and renal SLE (EXPLORER and LUNAR, respectively) did not achieve the primary goal $[4,5]$. In addition, adverse reactions such as hepatitis $B$ virus reactivation, opportunistic infections, malignancies, and inefficacy in AAV patients who were treated with rituximab have been reported in a Japanese cohort (RiCRAV) [6].

Currently, the TNF family ligands, B cell-activating factor (BAFF), a proliferation-inducing ligand (APRIL), and those receptors (BAFF receptor (BAFF-R), transmembrane activator and calcium modulator and cytophilin ligand interactor (TACI), B cell maturation antigen (BCMA), and proteoglycans) are found to play a prominent role in the pathogenesis of and are known as the potential therapeutic target for autoimmune diseases. In this review, we highlight the recent advance in the BAFF/APRIL-targeted therapy in systemic autoimmune diseases. 


\section{Pathological significance of the interaction between $B$ cells and Tfh cells}

Disturbances of $\mathrm{T}$ cell and B cell functions are involved in the development of autoimmune diseases [2, 7-11]. Activated $\mathrm{B}$ cells function as potent antigen-presenting cells and activate autoreactive $\mathrm{T}$ cells. The expression of costimulatory molecules, such as CD40 and CD80, is enhanced on B cells in autoimmune diseases such as SLE and is involved in the interactive activation with surrounding immunocompetent cells including autoreactive $\mathrm{T}$ cells $[8,9]$. In addition, RNA- or DNA-containing autoantigens co-ligate $\mathrm{B}$ cell receptors (BCRs) and Toll-like receptor (TLR)-7/9, leading to robust activation, proliferation, and differentiation of autoreactive B cells [12]. In SLE, autoantibodies produced by autoreactive B cells form immune complexes that deposit in tissues, leading to persistent inflammation and organ damage. Furthermore, it is well known that the number of memory $B$ cells and plasmablasts correlate with disease activity in SLE [13-15]. We reported previously that the proportions of $\mathrm{CD} 19^{+} \mathrm{IgD}^{-} \mathrm{CD} 27^{+}$class-switched memory $\mathrm{B}$ cells and $\mathrm{CD}_{1} 9^{+} \mathrm{IgD}^{-} \mathrm{CD} 27^{-}$effector memory B cells tended to be higher in the peripheral blood of refractory SLE patients than in that of the control [16-18]. In contrast, B regulatory (Breg) cells, which produce interleukin (IL)-10 and transforming growth factor- $\beta$ (TGF$\beta$ ) and suppress effector T cells, are defective in patients with SLE [19].

The differentiation of $\mathrm{CD}^{+} \mathrm{T}$ helper cells into functionally distinct helper $\mathrm{T}$ subsets is critical for the pathogenesis of autoimmune diseases [20, 21], especially since the active involvement of T helper (Th) 17 and $\mathrm{T}$ follicular helper (Tfh) cells and the dysfunction of $\mathrm{T}$ regulatory (Treg) cells have been reported [20, 22-27]. Among these subsets, the Tfh cells have emerged as a critical regulator of autoimmunity [22]. The Tfh cells provide $B$ cell help by promoting the class switching of B cells and are defined by the expression of the master regulator Bcl6 and effector cytokine IL-21, along with key surface molecules, such as PD-1, CXCR5, CD40L, and ICOS $[22,28]$. The CXCR5 expression allows Tfh cells to migrate from the $\mathrm{T}$ cell zone to the $\mathrm{B}$ cell follicle where they localize in the germinal center $(\mathrm{GC})$ and mediate $\mathrm{B}$ cell help via cell-cell contact using the co-stimulatory molecules CD40L and ICOS [22]. Thus, B-Tfh cell interaction is necessary for autoantibody production. In mice, the excessive activity of Tfh cells induces hyperactive GC formation and autoantibody production, leading to a SLE-like phenotype $[29,30]$. While we and others have reported the mechanism of Tfh differentiation, the exact role of this subset in patients remains elusive. High proportions of circulating Tfh cells, which are characterized as $\mathrm{CD} 4^{+} \mathrm{CXCR} 5^{+} \mathrm{ICOS}^{\text {high }} \mathrm{PD}-1^{\text {high }}$, have been described in SLE patients, and their level in the peripheral blood correlates with titers of autoantibodies and with disease severity [31, 32].

Taken together, these findings highlight the notion that activated $\mathrm{T}$ cells, in addition to activated B cells, may also be potentially involved in the pathogenesis of autoimmunity and that the interaction between activated B and Tfh cells may play an important role in autoantibody-driven autoimmune diseases.

\section{Pathological role of BAFF and APRIL in autoimmune diseases}

BAFF, also called B lymphocyte stimulator (BLyS), is a B cell activation factor which is mainly expressed by monocytes, macrophages, and activated T cells. BAFF can be expressed on the cell surface as a membrane-bound form or released as a soluble form after cleavage by furin. BAFF binds to three receptors, the BAFF-R, BCMA, or TACI, and regulates $B$ cell survival, differentiation, maturation, immunoglobulin class switching, and antibody production (Fig. 1) [33, 34]. BAFF-R is mainly expressed in immature $\mathrm{B}$ cells, whereas TACI and BCMA are expressed in matured memory B cells and plasma cells, respectively. In addition, APRIL, which is a homologous factor to BAFF, binds to TACI, BCMA, and proteoglycans (Fig. 1). APRIL forms heterotrimers with BAFF and enhances BAFFmediated B cell activation [35]. TACI binds with higher affinity to APRIL but lower affinity to BAFF, compared with other BAFF receptors. Although both BAFF and APRIL promote B cell survival and differentiation, there are complicated regulatory mechanisms according to the varieties of the receptors (BAFF-R, BCMA, or TACI) and the differentiation stage of $B$ cells, as described above. In addition to its effect on B cells, recent works have demonstrated that BAFF can promote $\mathrm{T}$ cell activation, proliferation, and differentiation [36]. Interestingly, Coquery et al. reported that BCMA negatively regulates Tfh cell expansion, while BAFF-R-mediated signaling promotes Tfh cell accumulation into GC in lupus-prone mice [37]. Thus, the balance between BCMA and BAFF-R signaling may control the development of Tfh cells, indicating that BAFF/APRIL regulate autoimmunity not only via survival and differentiation of B cell but also via expansion of Th cells.

Animal studies have shown that BAFF-deficient mice lack $B$ cell maturation and the knockout of BAFF in lupusprone mice showed a reduction of mortality and disease severity [38]. The transgenic mice for BAFF show an expanded B cell maturation and develop severe SLE, which is supported by evidence on increased concentrations of antidouble-stranded DNA (dsDNA) antibodies and immune complex deposition in the mesangium [34, 39-41]. In humans, the serum level of BAFF and APRIL is both elevated in patients with SLE and positively correlates with disease activity and serological markers such as anti- 


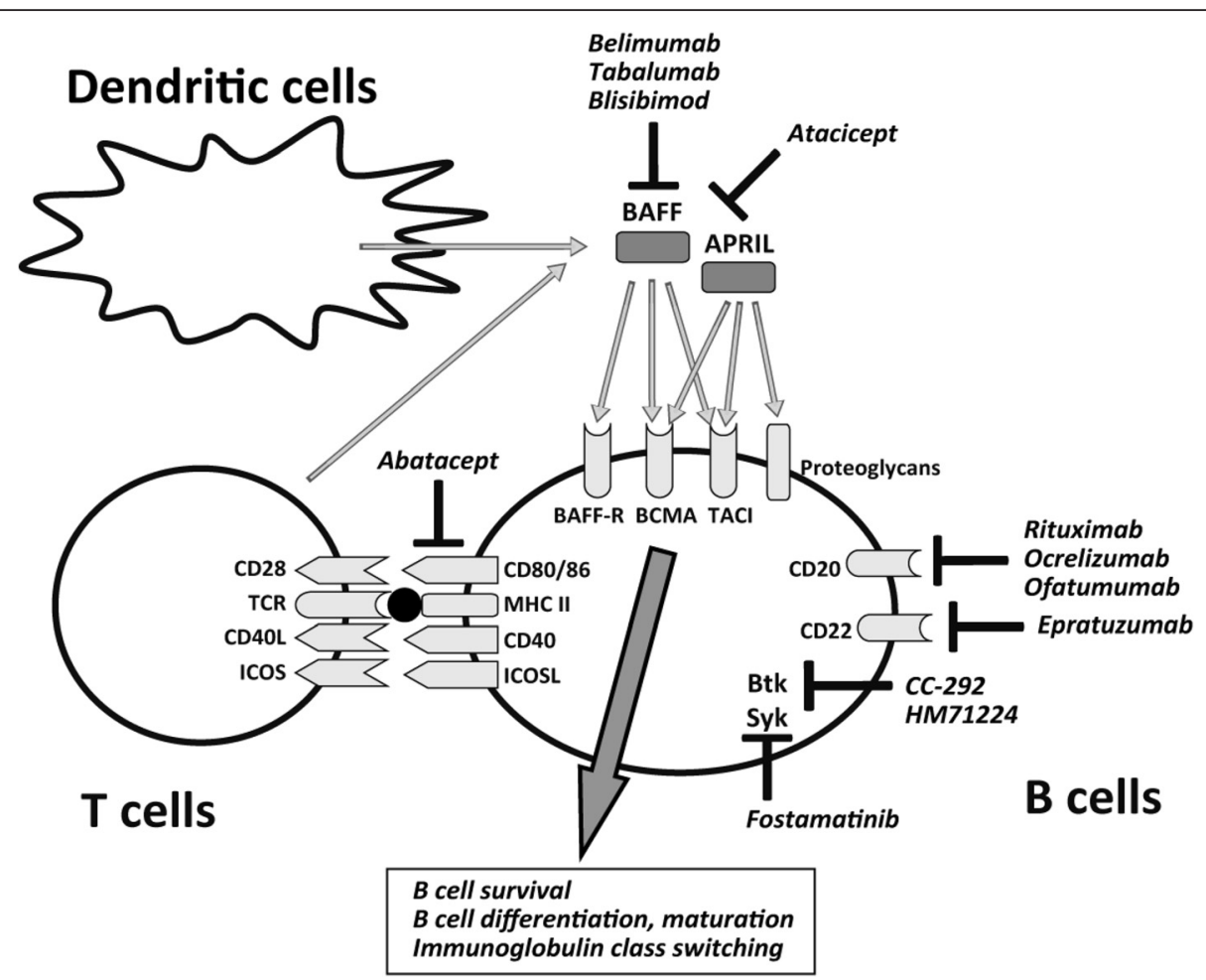

Fig. 1 Emerging B cell-targeted therapy including BAFF/APRIL inhibition in autoimmune diseases. Current strategies for autoimmune diseases include appropriate targets for therapeutic modulation such as B cell surface antigens (CD20 and CD22), co-stimulatory molecules (CTLA-4, CD40/ CD40L, ICOS/ICOSL, and BAFF/APRIL/BAFF-R/BCMA/TACI), and various intracellular signal transduction pathways (Syk and Btk)

dsDNA antibody levels $[42,43]$. There is a correlation between BAFF levels and circulating autoantibody levels in Sjogren's syndrome (SS) [44]. In addition, BAFF has been found to be elevated in the serum of AAV patients $[45,46]$. These results suggest a potential therapeutic strategy for patients with systemic autoimmune diseases by BAFF and/ or APRIL blockade.

\section{Targeting BAFF and APRIL in systemic autoimmune diseases}

\section{BAFF blockers}

Current strategies for autoimmune diseases include appropriate targets for therapeutic modulation such as B cell surface antigens (CD20 and CD22), co-stimulatory molecules (CTLA-4, CD40/CD40L, ICOS/ICOSL, and BAFF/ APRIL/BAFF-R/BCMA/TACI), and various intracellular signal transduction pathways (Syk and Btk) (Fig. 1) $[47,48]$. Selective inhibitors of BAFF and APRIL, which should ameliorate the pathogenesis by inhibiting autoreactive $\mathrm{B}$ cell activation and autoantibody production, are in clinical trials for autoimmune diseases (Fig. 1).

Belimumab is a fully human monoclonal antibody that antagonizes BAFF, thus inhibiting B cell survival and differentiation [49]. Belimumab directly reduces activation of naïve and transitional $\mathrm{B}$ cells and indirectly inhibits development of $\mathrm{IgD}^{-} \mathrm{CD} 27^{+}$class-switched memory B cells, plasmablasts, and plasma cells. The multicenter, randomized placebo-controlled double-blind phase III trials, BLISS-52 and BLISS-76, were performed to investigate the efficacy of belimumab at 1 or $10 \mathrm{mg} / \mathrm{kg}$ compared to placebo in the treatment of active SLE [50-52]. The primary end point was amelioration in SRI (SLE responder index), a composite measurement of SELENA-SLEDAI (Safety of Estrogens in Lupus Erythematosus National Assessment-Systemic Lupus Erythematosus Disease Activity Index), BILAG (British Isles Lupus Assessment Group) score, and physician global assessment. The BLISS-52 trial demonstrated that SRI rates at 52-week posttreatment were $44 \%, 51 \%(p=0.01)$, and $58 \%(p<0.01)$ in the placebo, belimumab $1 \mathrm{mg} / \mathrm{kg}$, and belimumab $10 \mathrm{mg} / \mathrm{kg}$ groups, respectively, suggesting a significant improvement of disease activity with an increased dose of this drug [51]. Belimumab has greater therapeutic benefit in patients with higher disease activity (SLEDAI $\geq 10$ ), anti-dsDNA positivity, or low complement [53]. No significant difference between the frequency of serious adverse reactions between the belimumab group and the placebo group was observed. Collectively, these results highlighted the efficacy and tolerability of belimumab as a novel biologic 
agent for the treatment of SLE, and the FDA approved this drug in 2011. However, the patients with active lupus nephritis were excluded in these trials. Therefore, it would be useful to investigate in future trials to elucidate the efficacy of belimumab in the patients with major organ involvements. Currently, the phase III trials to examine the efficacy and safety of belimumab in active lupus nephritis (NCT01639339) and in SLE patients located in Northeast Asia (NCT01345253) are ongoing.

Furthermore, belimumab is currently undergoing clinical trials in SS and AAV. In the phase II trial in 30 patients with primary SS (BELISS), $60 \%$ of the patients were responders and systemic activity scores measured by the EULAR SS disease activity index (ESSDAI) were significantly improved [54, 55]. Since this is an open-label trial, further randomized controlled trials are warranted. The phase III multicenter, randomized, double-blind study to evaluate the efficacy and safety of belimumab in combination with azathioprine for the maintenance of remission in GPA and MPA (BREVAS) is ongoing (NCT01663623) [56, 57].

Other anti-BAFF agents, tabalumab and blisibimod, are also being assessed in phase III randomized placebo-controlled trials to evaluate their efficacy in SLE. Tabalumab is a monoclonal antibody that neutralizes BAFF in both membrane-bound form and soluble form, whereas belimumab is thought to target the soluble form only. In rheumatoid arthritis (RA), tabalumab showed clinical efficacy in phase II trials in patients with an inadequate response to methotrexate (MTX) [58, 59]. However, the phase III trial demonstrated that tabalumab did not provide the degree of clinical efficacy in moderate-severe RA, taking the MTX observed with other approved biological agents [60]. Based on these findings, the pharmaceutical company discontinued the phase III trial for RA. In addition, the phase III clinical trials for tabalumab in moderate to severe SLE (ILLUMINATE-2) met its primary end point only at higher doses but failed to meet secondary end points [61]. The pharmaceutical company also discontinued the development of this drug for SLE.

Blisibimod is a human "peptibody," which binds to both cell membrane-expressed and soluble BAFF and antagonizes BAFF, and has recently been evaluated in a phase II clinical trial (PEARL-SC) [62]. In this study, the significant reductions in proteinuria and anti-dsDNA and significant increases in $\mathrm{C} 3$ were observed with the blisibimod group. Currently, a phase III study to examine the efficacy and safety of blisibimod in patients with active SLE (NCT01395745) is under way.

Briobacept, a protein containing both IgG and the ligand of BAFF-R, which antagonizes BAFF did not show sufficient efficacy in a phase II trial (ATLAS) (NCT01499355) and was terminated.

\section{TACI-Ig: atacicept}

Atacicept, a recombinant fusion protein containing both the Fc portion of the human IgG1 and the extracellular domain of TACI $[63,64]$, binds to APRIL and BAFF and inhibits activation of TACI-mediated signaling. The phase I trial in moderately active SLE showed that atacicept resulted in a $60 \%$ reduction in mature B cells and a $45 \%$ attenuation of immunoglobulin compared to placebo [65]. There were no significant differences in the levels of adverse reactions between atacicept and placebo. However, the phase II clinical trial in patients with active lupus nephritis who are taking steroids and MMF was terminated due to severe infection [66]. Isenberg et al. reported recently the results of a randomized phase II/III trial of atacicept that sought to determine the efficacy and safety of atacicept in the prevention of flares in SLE [67]. The results with a high dose of atacicept were encouraging, but there are severe concerns about the infections. Currently, the phase III clinical trials for atacicept in patients who have no major organ involvements (ADDRESS II) (NCT01972568, NCT02070978) are under way. In Japan, a phase IIb trial in patients with SLE is in progress.

\section{Conclusions}

BAFF and APRIL play a prominent role in the pathogenesis of autoimmune diseases. Indeed, a certain number of patients receive benefit from BAFF/APRIL-blocking therapies. On the other hand, several clinical trials have demonstrated the efficacy of the BAFF/APRIL blockade which showed considerable variability in the response to $\mathrm{B}$ cell-targeted therapy. Furthermore, increasing evidence points to substantial heterogeneity in the pathogenesis of autoimmune diseases; thus, B cell-targeted therapy may be ineffective in some patients but effective in others. Therefore, objective markers that can predict the effect of BAFF/APRIL-blocking agents should be valuable to the precision medicine linked clinically and to cost-effective therapy.

\section{Abbreviations}

AAV: ANCA-associated vasculitis; APRIL: a proliferation-inducing ligand; BAFF: B cell-activating factor; BCMA: B cell maturation antigen; BCR: B cell receptor; BILAG: British Isles Lupus Assessment Group; BLyS: B lymphocyte stimulator; Breg: B regulatory; ESSDAI: EULAR SS disease activity index; GC: germinal center; GPA: granulomatosis with polyangitis; IL: interleukin; MPA: microscopic polyangitis; MTX: methotrexate; RA: rheumatoid arthritis; SELENA: Safety of Estrogens in Lupus Erythematosus National Assessment; SLE: systemic lupus erythematosus; SLEDAl: Systemic Lupus Erythematosus Disease Activity Index; SRI: SLE responder index; SS: Sjogren's syndrome; TACl: transmembrane activator and calcium modulator and cytophilin ligand interactor; Tfh: T follicular helper; TGF: transforming growth factor; TLR: Toll-like receptor; Treg: T regulatory.

\section{Competing interests}

Y. Tanaka has received consulting fees, lecture fees, and/or honoraria from Mitsubishi-Tanabe, Eisai, Chugai, Abbott Japan, Astellas, Daiichi-Sankyo, Abbvie, Janssen, Pfizer, Takeda, Astra-Zeneca, Eli Lilly Japan, GlaxoSmithKline, Quintiles, MSD, and Asahi-Kasei and has received research grants from Bristol-Myers, Mitsubishi-Tanabe, Abbvie, MSD, Chugai, Astellas, and Daiichi-Sankyo. S. Nakayamada declares no conflict of interest. 


\section{Authors' contributions}

SN and YT contributed to the overall review and writing of the manuscript. Al authors enrolled and clinically managed the study patients, and Both authors read and approved the final manuscript.

\section{Funding}

This work was supported in part by Research on Rare and Intractable Diseases and Research Grant-In-Aid for Scientific Research by the Ministry of Health, Labor and Welfare of Japan; the Ministry of Education, Culture, Sports, Science and Technology of Japan; and the University of Occupational and Environmental Health, Japan, and UOEH Grant for Advanced Research.

\section{Received: 5 April 2016 Accepted: 10 May 2016}

Published online: 21 July 2016

\section{References}

1. Arbuckle MR, McClain MT, Rubertone MV, et al. Development of autoantibodies before the clinical onset of systemic lupus erythematosus. N Engl J Med. 2003; 349:1526-33.

2. Liu Z, Davidson A. Taming lupus-a new understanding of pathogenesis is leading to clinical advances. Nat Med. 2012;18:871-82.

3. Tanaka $Y$, Yamamoto $K$, Takeuchi $T$, et al. A multicenter phase I/II trial of rituximab for refractory systemic lupus erythematosus. Mod Rheumatol. 2007;17:191-7

4. Merrill JT, Neuwelt CM, Wallace DJ, et al. Efficacy and safety of rituximab in moderately-to-severely active systemic lupus erythematosus: the randomized, double-blind, phase II/III systemic lupus erythematosus evaluation of rituximab trial. Arthritis Rheum. 2010;62:222-33.

5. Rovin BH, Furie R, Latinis $\mathrm{K}$, et al. Efficacy and safety of rituximab in patients with active proliferative lupus nephritis: the Lupus Nephritis Assessment with Rituximab study. Arthritis Rheum. 2012:64:1215-26.

6. Nagafuchi H, Atsumi T, Hatta K, et al. Long-term safety and efficacy of rituximab in 7 Japanese patients with ANCA-associated vasculitis. Mod Rheumatol. 2015;25:603-8.

7. Nakayamada S, Saito K, Nakano K, Tanaka Y. Activation signal transduction by beta1 integrin in T cells from patients with systemic lupus erythematosus. Arthritis Rheum. 2007:56:1559-68.

8. Desai-Mehta A, Lu L, Ramsey-Goldman R, Datta SK. Hyperexpression of CD40 ligand by B and T cells in human lupus and its role in pathogenic autoantibody production. J Clin Invest. 1996;97:2063-73.

9. Grammer AC, Slota R, Fischer $\mathrm{R}$, et al. Abnormal germinal center reactions in systemic lupus erythematosus demonstrated by blockade of CD154-CD40 interactions. J Clin Invest. 2003;112:1506-20.

10. Crispin JC, Kyttaris V, Juang YT, Tsokos GC. Systemic lupus erythematosus: new molecular targets. Ann Rheum Dis. 2007;66 Suppl 3:iii65-9.

11. Tsokos GC. Systemic lupus erythematosus. N Engl J Med. 2011:365:2110-21.

12. Avalos AM, Busconi L, Marshak-Rothstein A. Regulation of autoreactive B cell responses to endogenous TLR ligands. Autoimmunity. 2010:43:76-83.

13. Jacobi AM, Reiter K, Mackay M, et al. Activated memory B cell subsets correlate with disease activity in systemic lupus erythematosus: delineation by expression of CD27, IgD, and CD95. Arthritis Rheum. 2008:58:1762-73.

14. Jacobi AM, Odendahl M, Reiter K, et al. Correlation between circulating CD27high plasma cells and disease activity in patients with systemic lupus erythematosus. Arthritis Rheum. 2003;48:1332-42.

15. Anolik JH, Barnard J, Owen T, et al. Delayed memory B cell recovery in peripheral blood and lymphoid tissue in systemic lupus erythematosus after B cell depletion therapy. Arthritis Rheum. 2007:56:3044-56.

16. Iwata S, Saito K, Tokunaga M, Tanaka Y. Persistent memory B cell downregulation after 6-year remission induced by rituximab therapy in patients with systemic lupus erythematosus. Lupus. 2013;22:538-40.

17. Iwata S, Saito K, Tokunaga M, et al. Phenotypic changes of lymphocytes in patients with systemic lupus erythematosus who are in longterm remission after B cell depletion therapy with rituximab. J Rheumatol. 2011;38:633-41.

18. Tokunaga M, Fujii K, Saito K, et al. Down-regulation of CD40 and CD80 on B cells in patients with life-threatening systemic lupus erythematosus after successful treatment with rituximab. Rheumatology (Oxford). 2005:44:176-82

19. Blair PA, Norena LY, Flores-Borja F, et al. CD19(+)CD24(hi)CD38(hi) B cells exhibit regulatory capacity in healthy individuals but are functionally impaired in systemic lupus erythematosus patients. Immunity. 2010;32:129-40.

20. Nakayamada S, Takahashi H, Kanno Y, O'Shea JJ. Helper T cell diversity and plasticity. Curr Opin Immunol. 2012;24:297-302.
21. O'Shea JJ, Paul WE. Mechanisms underlying lineage commitment and plasticity of helper CD4+ T cells. Science. 2010;327:1098-102.

22. Crotty S. Follicular helper CD4 T cells (TFH). Annu Rev Immunol. 2011;29:621-63.

23. Nakayamada S, Kanno Y, Takahashi H, et al. Early Th1 cell differentiation is marked by a Tfh cell-like transition. Immunity. 2011;35:919-31.

24. Shin MS, Lee N, Kang I. Effector T-cell subsets in systemic lupus erythematosus: update focusing on Th17 cells. Curr Opin Rheumatol. 2011;23:444-8.

25. Tangye SG, Ma CS, Brink R, Deenick EK. The good, the bad and the ugly-TFH cells in human health and disease. Nat Rev Immunol. 2013;13:412-26.

26. Bonelli M, Smolen JS, Scheinecker C. Treg and lupus. Ann Rheum Dis. 2010;69 Suppl 1:i65-6

27. Miyara M, Gorochov G, Ehrenstein M, Musset L, Sakaguchi S, Amoura Z. Human FoxP3+ regulatory T cells in systemic autoimmune diseases. Autoimmun Rev. 2011;10:744-55.

28. Schwartzberg PL, Mueller KL, Oi H, Cannons JL. SLAM receptors and SAP influence lymphocyte interactions, development and function. Nat Rev Immunol. 2009:9:39-46.

29. Vinuesa CG, Cook MC, Angelucci C, et al. A RING-type ubiquitin ligase family member required to repress follicular helper T cells and autoimmunity. Nature. 2005;435:452-8.

30. Linterman MA, Rigby RJ, Wong RK, et al. Follicular helper T cells are required for systemic autoimmunity. J Exp Med. 2009;206:561-76.

31. Simpson N, Gatenby PA, Wilson A, et al. Expansion of circulating T cells resembling follicular helper $T$ cells is a fixed phenotype that identifies a subset of severe systemic lupus erythematosus. Arthritis Rheum. 2010;62:234-44.

32. Le Coz C, Joublin A, Pasquali JL, Korganow AS, Dumortier H, Monneaux F. Circulating TFH subset distribution is strongly affected in lupus patients with an active disease. PLoS One. 2013;8, e75319.

33. Bossen C, Schneider P. BAFF, APRIL and their receptors: structure, function and signaling. Semin Immunol. 2006;18:263-75.

34. Chan VS, Tsang HH, Tam RC, Lu L, Lau CS. B-cell-targeted therapies in systemic lupus erythematosus. Cell Mol Immunol. 2013;10:133-42.

35. Mackay F, Ambrose C. The TNF family members BAFF and APRIL: the growing complexity. Cytokine Growth Factor Rev. 2003;14:311-24.

36. Chen M, Lin X, Liu Y, et al. The function of BAFF on Thelper cells in autoimmunity. Cytokine Growth Factor Rev. 2014;25:301-5.

37. Coquery CM, Loo WM, Wade NS, et al. BAFF regulates follicular helper $t$ cells and affects their accumulation and interferon-gamma production in autoimmunity. Arthritis Rheumatol. 2015;67:773-84.

38. Jacob CO, Pricop L, Putterman C, et al. Paucity of clinical disease despite serological autoimmunity and kidney pathology in lupus-prone New Zealand mixed 2328 mice deficient in BAFF. J Immunol. 2006;177:2671-80.

39. Groom JR, Fletcher CA, Walters SN, et al. BAFF and MyD88 signals promote a lupuslike disease independent of T cells. J Exp Med. 2007;204:1959-71.

40. Mackay F, Schneider P, Rennert P, Browning JBAFFAND. APRIL: a tutorial on B cell survival. Annu Rev Immunol. 2003;21:231-64.

41. Shulga-Morskaya S, Dobles M, Walsh ME, et al. B cell-activating factor belonging to the TNF family acts through separate receptors to support B cell survival and T cell-independent antibody formation. J Immunol. 2004;173:2331-41.

42. Chu VT, Enghard $P$, Schurer $S$, et al. Systemic activation of the immune system induces aberrant BAFF and APRIL expression in B cells in patients with systemic lupus erythematosus. Arthritis Rheum. 2009;60:2083-93.

43. Zollars E, Bienkowska J, Czerkowicz J, et al. BAFF (B cell activating factor) transcript level in peripheral blood of patients with SLE is associated with same-day disease activity as well as global activity over the next year. Lupus Sci Med. 2015;2, e000063.

44. Mariette X, Roux S, Zhang J, et al. The level of BLyS (BAFF) correlates with the titre of autoantibodies in human Sjogren's syndrome. Ann Rheum Dis. 2003:62:168-71.

45. Nagai M, Hirayama K, Ebihara I, Shimohata H, Kobayashi M, Koyama A. Serum levels of BAFF and APRIL in myeloperoxidase anti-neutrophil cytoplasmic autoantibody-associated renal vasculitis: association with disease activity. Nephron Clin Pract. 2011;118:C339-45.

46. Bader L, Koldingsnes W, Nossent J. B-lymphocyte activating factor levels are increased in patients with Wegener's granulomatosis and inversely correlated with ANCA titer. Clin Rheumatol. 2010:29:1031-5.

47. Kamal A, Khamashta M. The efficacy of novel B cell biologics as the future of SLE treatment: a review. Autoimmun Rev. 2014;13:1094-101.

48. Nakayamada S, Iwata S, Tanaka Y. Relevance of lymphocyte subsets to B cell-targeted therapy in systemic lupus erythematosus. Int J Rheum Dis. 2015;18:208-18. 
49. Sanz I, Lee FE. B cells as therapeutic targets in SLE. Nat Rev Rheumatol. 2010;6:326-37.

50. Furie R, Petri M, Zamani O, et al. A phase III, randomized, placebo-controlled study of belimumab, a monoclonal antibody that inhibits B lymphocyte stimulator, in patients with systemic lupus erythematosus. Arthritis Rheum. 2011;63:3918-30.

51. Navarra SV, Guzman RM, Gallacher AE, et al. Efficacy and safety of belimumab in patients with active systemic lupus erythematosus: a randomised, placebo-controlled, phase 3 trial. Lancet. 2011;377:721-31.

52. Manzi S, Sanchez-Guerrero J, Merrill JT, et al. Effects of belimumab, a B lymphocyte stimulator-specific inhibitor, on disease activity across multiple organ domains in patients with systemic lupus erythematosus: combined results from two phase III trials. Ann Rheum Dis. 2012;71:1833-8.

53. van Vollenhoven RF, Petri MA, Cervera $R$, et al. Belimumab in the treatment of systemic lupus erythematosus: high disease activity predictors of response. Ann Rheum Dis. 2012;71:1343-9.

54. Mariette X, Seror R, Quartuccio L, et al. Efficacy and safety of belimumab in primary Sjogren's syndrome: results of the BELISS open-label phase II study. Ann Rheum Dis. 2015;74:526-31.

55. Seror R, Nocturne G, Lazure T, et al. Low numbers of blood and salivary natural killer cells are associated with a better response to belimumab in primary Sjogren's syndrome: results of the BELISS study. Arthritis Res Ther. 2015;17:241.

56. Lenert A, Lenert P. Current and emerging treatment options for ANCAassociated vasculitis: potential role of belimumab and other BAFF/APRIL targeting agents. Drug Des Devel Ther. 2015;9:333-47.

57. Lutalo PM, D'Cruz DP. Biological drugs in ANCA-associated vasculitis. Int Immunopharmacol. 2015;27:209-12.

58. Genovese MC, Lee E, Satterwhite J, et al. A phase 2 dose-ranging study of subcutaneous tabalumab for the treatment of patients with active rheumatoid arthritis and an inadequate response to methotrexate. Ann Rheum Dis. 2013;72:1453-60.

59. Genovese MC, Bojin S, Biagini IM, et al. Tabalumab in rheumatoid arthritis patients with an inadequate response to methotrexate and naive to biologic therapy: a phase II, randomized, placebo-controlled trial. Arthritis Rheum. 2013;65:880-9.

60. Smolen JS, Weinblatt ME, van der Heijde D, et al. Efficacy and safety of tabalumab, an anti-B-cell-activating factor monoclonal antibody, in patients with rheumatoid arthritis who had an inadequate response to methotrexate therapy: results from a phase III multicentre, randomised, double-blind study. Ann Rheum Dis. 2015;74:1567-70.

61. Merrill JT, van Vollenhoven RF, Buyon JP, et al. Efficacy and safety of subcutaneous tabalumab, a monoclonal antibody to B-cell activating factor, in patients with systemic lupus erythematosus: results from ILLUMINATE-2, a 52-week, phase III, multicentre, randomised, double-blind, placebo-controlled study. Ann Rheum Dis. 2016;75:332-40.

62. Furie RA, Leon $\mathrm{G}$, Thomas $\mathrm{M}$, et al. A phase 2, randomised, placebo-controlled clinical trial of blisibimod, an inhibitor of B cell activating factor, in patients with moderate-to-severe systemic lupus erythematosus, the PEARL-SC study. Ann Rheum Dis. 2015;74:1667-75.

63. Gregersen JW, Jayne DR. B-cell depletion in the treatment of lupus nephritis. Nat Rev Nephrol. 2012;8:505-14.

64. La Cava A. Targeting B cells with biologics in systemic lupus erythematosus. Expert Opin Biol Ther. 2010;10:1555-61.

65. Dall'Era M, Chakravarty E, Wallace D, et al. Reduced B lymphocyte and immunoglobulin levels after atacicept treatment in patients with systemic lupus erythematosus: results of a multicenter, phase $\mathrm{lb}$, double-blind, placebo-controlled, dose-escalating trial. Arthritis Rheum. 2007;56:4142-50.

66. Ginzler EM, Wax S, Rajeswaran A, et al. Atacicept in combination with MMF and corticosteroids in lupus nephritis: results of a prematurely terminated trial. Arthritis Res Ther. 2012;14:R33.

67. Isenberg D, Gordon C, Licu D, Copt S, Rossi CP, Wofsy D. Efficacy and safety of atacicept for prevention of flares in patients with moderate-to-severe systemic lupus erythematosus (SLE): 52-week data (APRIL-SLE randomised trial). Ann Rheum Dis. 2015;74:2006-15.

\section{Submit your next manuscript to BioMed Central and we will help you at every step:}

- We accept pre-submission inquiries

- Our selector tool helps you to find the most relevant journal

- We provide round the clock customer support

- Convenient online submission

- Thorough peer review

- Inclusion in PubMed and all major indexing services

- Maximum visibility for your research

Submit your manuscript at www.biomedcentral.com/submit
() BioMed Central 